PALABRAS CLAVE

Integración económica

Comercio intrarregional

Productos industriales

Comercio sur-sur

Exportaciones

Importaciones

Estadísticas comerciales

Argentina

Mercosur

Marta Bekerman

Investigadora Principal del Consejo

Nacional de Investigaciones Científicas y

Técnicas (CONICET)

œmarbekerman@gmail.com

Cecilia Rikap

Investigadora y docente de la Facultad

de Ciencias Económicas,

Universidad de Buenos Aires

œ ceciliarikap@gmail.com
REVISTA CEPAL 100 ABRIL 2010

\section{Integración regional y} diversificación de exportaciones en el Mercosur:

\section{el caso de Argentina y Brasil}

\author{
Marta Bekerman y Cecilia Rikap
}

$\mathrm{S}$

analizan los efectos del comercio argentino con sus socios del Mercosur en dos períodos clave: antes (1997-1998) y después (20052006) de las crisis de sus economías. Para examinar la repercusión del comercio en la regionalización de las exportaciones e importaciones de los países miembros se utilizó el índice de orientación regional empleado por Yeats al estudiar estos países para otro período. Se concluye que los resultados alcanzados por Yeats se contradicen con la realidad posterior de Argentina y Brasil, a los que el Mercosur permitió, mediante procesos de aprendizaje, aumentar el comercio con países exteriores al bloque. Este efecto positivo se sintió principalmente en Brasil y no tanto en los demás miembros, especialmente Uruguay y Paraguay, debido a las asimetrías subyacentes entre las economías de estos países que determinaron que el país más grande sea el principal beneficiado de la integración hasta el presente. 


\section{I}

\section{Introducción}

La forma de evaluar el efecto de los procesos de integración regional en el comercio de bienes ha motivado profundas discusiones. Para algunos autores ese efecto puede ser positivo en tanto no produzca desvíos de comercio. Para otros, será más beneficioso cuando genere ventajas comparativas dinámicas, a partir de las posibilidades que ofrece la presencia de un mercado ampliado y la colaboración en los campos tecnológicos y del aprendizaje.

En el caso del Mercosur, hasta 1998 las exportaciones intrarregionales no solo mostraron una alta tasa de crecimiento, sino también un patrón de especialización mucho más diversificado que las exportaciones del Mercosur. Esto condujo a autores como Yeats a considerar que el comercio de la región venía generando, desde su creación, procesos de desvío de comercio. En efecto, en sus estudios sobre el comportamiento comercial que presentaba el Mercosur desde sus inicios hasta mediados de los años noventa, este autor constata un proceso de regionalización a través de la expansión de las exportaciones de sectores en que los países miembros no gozaban de ventajas comparativas con respecto a otros mercados. Dentro de este grupo Yeats mencionaba, entre otros, los casos de los productos químicos y plásticos, las maquinarias y la industria automotriz y de partes para vehículos. La pérdida de eficiencia resultante tendría una incidencia negativa no solo para terceros países, sino también en los propios países miembros al renunciar a aquellos beneficios que podrían derivarse de una especialización basada en sus ventajas comparativas (Yeats, 1997)

En este trabajo se apuntará, en primer lugar, a discutir esta concepción planteada por Yeats, contraponiéndola con la presentada por otros autores que enfatizan la importancia de la generación de ventajas comparativas dinámicas en el ámbito de los acuerdos de integración regional. Por otra parte, se analizará —desde la perspectiva de Argentina en su comercio con Brasil, Paraguay y Uruguay-cuál fue la evolución comercial reciente de aquellos bienes industriales que hacia 1998 mostraban altos niveles de regionalización (en importaciones, exportaciones o en ambos). ${ }^{1}$ Se intentará observar en qué casos esos niveles de regionalización se acentuaron o redujeron y si dieron lugar o no al desarrollo de ventajas comparativas dinámicas tanto en el interior del bloque como en relación con terceros mercados. Esto tal vez permita entender cuál fue el posterior comportamiento comercial de aquellos sectores que Yeats y otros autores catalogaron en su momento como ineficientes, por no responder a las ventajas comparativas estáticas de estos países.

En la primera sección, se realizará un análisis comparativo de los distintos planteamientos sobre el comercio sur-sur, la integración regional y el caso del Mercosur en particular. En la segunda sección, se observará la evolución del comercio entre Argentina y Brasil de bienes industriales con altos niveles de regionalización entre dos períodos en estudio: uno previo a las crisis macroeconómicas vividas por ambos países (1997-1998) y el otro más reciente (2005-2006). En la tercera sección, se profundizará el análisis de la sección anterior tomando en cuenta índices que permitan comprender la evolución que muestra el comercio intra y extrarregional, para destacar aquellos sectores con bienes industriales regionalizados en al menos uno de los períodos en estudio. En el cuarto apartado se observarán los mismos indicadores para el comercio de Argentina con Uruguay y Paraguay. Finalmente, en el quinto apartado se resumirán las conclusiones del trabajo.

\footnotetext{
${ }^{1}$ Para tal efecto se trabajará con el índice de regionalización que utiliza Yeats (1997).
} 


\section{II \\ El impacto de la integración regional según distintas posiciones teóricas}

Existe una amplia literatura acerca del comercio internacional y su relación con los procesos de integración. En este trabajo se presentarán dos posiciones opuestas sobre el comercio sur-sur que afectan directamente al análisis de las relaciones en el Mercosur y particularmente entre Argentina y Brasil, países que representan más del 90\% del comercio de la región.

En primer lugar se encuentran aquellos planteamientos en que se considera que la existencia de un comercio sur-sur de productos manufacturados intensivos en capital, que no se extiende a terceros mercados, podría estar reflejando un desvío ineficiente de comercio. Este tipo de intercambio, por lo tanto, debería restringirse o eliminarse en pos de una división internacional del trabajo en la que cada economía produzca aquellos bienes para los que es más eficiente en términos de ventajas comparativas estáticas. Dentro de los modelos que propugnan un desarrollo del comercio basado en una dotación dada de factores, se destaca el correspondiente a Heckscher y Ohlin, que se sustenta en un conjunto de supuestos tales como: la tecnología se considera fija y disponible para todos; los factores productivos son homogéneos y presentan rendimientos constantes a escala; hay pleno empleo y distintas intensidades factoriales de los bienes de los distintos países; cada mercancía es siempre intensiva en un factor dado, es decir, no hay reversibilidad de la función de producción. ${ }^{2}$ De estos puntos se desprende el supuesto fundamental de que se trata de mercados en competencia perfecta y se concluye que el patrón más eficiente de comercio de cada país dependerá de su dotación factorial, es decir, de la abundancia relativa en alguno de los factores productivos (capital o trabajo). Aplicado al caso argentino-brasileño significaría postular, de acuerdo con la división internacional del trabajo, que el Mercosur debería producir relativamente más bienes intensivos en trabajo, exportar esos bienes e importar los bienes más intensivos, relativamente, en capital.

Estas ideas son retomadas por Corden para analizar las consecuencias de las uniones de comercio. Para este autor toda unión comercial es beneficiosa si

${ }^{2}$ Para una presentación detallada de los supuestos del modelo de Hecksher-Olhin, véase Krugman y Obstfeld (2001). genera creación de comercio. Por el contrario, ella será negativa si provoca desvíos de comercio (en favor de los países pertenecientes a la unión) que de no existir una situación arancelaria preferencial no se hubieran producido (Corden, 1972).

A partir del concepto de creación y desvío de comercio que se presentan ante las integraciones o uniones comerciales de varios países, Yeats (1997) se propone analizar el caso del Mercosur. La primera pregunta que se plantea es si los aumentos que muestran ciertas exportaciones intrarregionales a partir de la conformación del bloque fueron consistentes con las ventajas comparativas de los países miembros. Siguiendo a Corden, Yeats indagó — para el período 1988-1994— si esas exportaciones por parte de los socios del Mercosur tenían también lugar con otros países del mundo. Para ello, utilizó el índice de orientación regional y un índice de ventajas comparativas reveladas (VCR) que excluye el comercio dentro del Mercosur como forma de reflejar la capacidad de los países del bloque para competir en mercados en que no contaban con beneficios comerciales discriminatorios. ${ }^{3}$

Este autor observa que gran parte del dinamismo que muestran las exportaciones intrarregionales de ciertos bienes seleccionados se relaciona con un cambio en la orientación regional en favor del Mercosur. Es que en aquellos productos para los que el comercio ha crecido más dentro de la región, los países miembros no muestran competitividad a nivel de terceros mercados, por lo que existe escasa evidencia de que presenten ventajas comparativas (estáticas) en relación con ellos. Por lo tanto, lejos de alcanzar efectos de expansión o creación de comercio, el Mercosur generó desvíos ineficientes al promover el intercambio de bienes intensivos en capital que no eran exportados en una proporción similar hacia el resto del mundo.

Desde la perspectiva de Yeats y otros autores de esta corriente, en la medida en que Argentina y Brasil no se especialicen en la exportación de bienes intensivos en el factor relativamente abundante (productos primarios

\footnotetext{
${ }^{3}$ La metodología de cálculo del índice de orientación regional puede verse en el Anexo 1.
} 
o manufacturas de origen agropecuario intensivas en trabajo), no solo estarán generando pérdidas de comercio para terceros países, sino también para sus propios consumidores.

Los planteamientos de Yeats han sido refutados desde diversas perspectivas. Una de ellas critica el hecho de que este autor solo analice el comportamiento de las exportaciones dentro del Mercosur. Si bien ellas aumentaron hasta el año 1998, esto coincide con un fuerte incremento en las importaciones desde terceros países. Por eso no se puede generalizar un concepto de desvío de comercio que haya generado pérdidas para los países no pertenecientes al bloque (Laird, 1998; Nagarajan, 1998; Ríos, 2003). En una oposición más frontal se presentan quienes señalan que el comercio sur-sur de productos industriales es beneficioso más allá de las dotaciones dadas de factores, puesto que puede brindar herramientas para el desarrollo de economías de escala y procesos de aprendizaje que permitirán generar ventajas comparativas dinámicas tanto a nivel intra como extrarregional.

Dentro de este grupo se destaca Amsden (1997), quien crítica con fuerza el supuesto de la existencia de solo dos factores productivos, capital y trabajo, incorporado en el modelo de Heckscher y Ohlin. En particular, porque esto implica considerar al trabajo como un factor homogéneo e ignorar o minimizar el papel del trabajo calificado, que es el que se emplea en forma intensiva en las que denomina "industrias calificadas" (skilled industries). Se trata de sectores en que se observan las mayores posibilidades de generar efectos de aprendizaje, por lo que sus exportaciones — si bien en un principio pueden ser solo sur-sur- en un futuro podrían expandirse hacia los países centrales. En esta explicación cobra importancia la utilización del concepto de ventajas comparativas dinámicas en oposición al de ventajas comparativas estáticas que reivindica el otro grupo de autores. En un contexto como el planteado por
Amsden, un sector puede no ser eficiente en un país en un momento del tiempo, pero una tasa de crecimiento de su productividad mayor que la correspondiente a dicho sector en un segundo país puede determinar que en un futuro sí lo sea.

Esta posición es compartida, entre otros autores, por Rodrik, quien puntualiza los diversos factores que justificarían el aumento del comercio y la creación de bloques entre países en desarrollo. Entre ellos destaca la existencia de mercados imperfectos y de rendimientos a escala en un contexto en que el comercio se da entre países cada vez más asimétricos (en cuanto a tamaño, grado de ventaja inicial o ventaja comparativa estática). Esto hace que también sean asimétricos los efectos que dicho comercio puede provocar en el crecimiento, peligro que podría reducirse en la medida que se impulsara un proceso de integración entre países en desarrollo más "similares" entre sí (Rodrik, 1995).

Este autor señala como necesario que los países en desarrollo planteen una estrategia de producción y exportación de manufacturas que podría ser reforzada desde el interior de un bloque comercial. Enfocar sus esfuerzos hacia el desarrollo de sectores manufactureros que luego puedan ser exportados a terceros mercados le otorga un especial sentido a la expansión del comercio sur-sur. ${ }^{4}$

Vale decir que el acceso seguro a nuevos mercados similares entre sí puede convertirse en una plataforma para acceder luego a otros mercados fuera del bloque. Para Rodrik y Amsden esto implica adquirir ventajas comparativas dinámicas, al tiempo que se avanza en procesos de industrialización.

\footnotetext{
${ }^{4}$ Siguiendo esta línea de pensamiento, Ffrench-Davis (2001) rescata una cita de Prebisch quien "recomendaba con fuerza el estímulo a las exportaciones de manufacturas entre los países latinoamericanos, con acuerdos preferenciales", principalmente a aquellas con mayor absorción de tecnología y mayor elasticidad ingreso.
} 


\section{III}

\section{El comercio sur-sur: la perspectiva del Mercosur}

Para que los países que promueven un proceso de integración puedan alcanzar ventajas comparativas dinámicas es necesario contar con regulaciones que armonicen las asimetrías tanto estructurales como normativas que puedan existir entre ellos. De lo contrario, el desarrollo del bloque puede contribuir a profundizar las asimetrías existentes y a generar tensiones que terminen limitando el propio desempeño del proceso de integración.

Diversos autores vienen alertando sobre la existencia de marcadas asimetrías en el seno del Mercosur, situación que lejos de corregirse a partir de la creación del bloque, se viene agravando con el tiempo (Carrera, 2005; Bekerman, Sirlin y Streb, 1995). Es más, para Ríos (2003) las diferencias que presentan las estructuras productivas de los países miembros se han convertido hoy en el principal escollo que enfrenta el proceso de integración. Es por ello que esta autora recomienda disciplinar el uso de incentivos a la producción y a la inversión, así como diseñar y aplicar instrumentos adecuados para reducir tales diferencias.

Estas recomendaciones son extendidas a las políticas sectoriales por algunos autores. Se plantea que para que la implementación del arancel externo común sea sustentable en el tiempo se requiere una coordinación de los regímenes de reconversión industrial y de comercio exterior, para los efectos de que no se generen - como consecuencia de dichos regímenes- modificaciones abruptas en las condiciones competitivas de cada uno de los países miembros (Bekerman, Sirlin y Streb, 1995).

Pero está claro que el Mercosur no presenta un proyecto de desarrollo de la estructura productiva conjunto o armonizado. Por lo tanto, la falta de proyectos comunes de largo plazo ha derivado en que el país más dinámico dentro del bloque, Brasil, se beneficie en mayor medida de los procesos de aprendizaje antes mencionados. La existencia en ese país de determinadas regulaciones, así como de incentivos a sectores clave, permitió asegurar la continuidad del crecimiento de la productividad y la inversión sin los altibajos que se observan en el caso argentino. Por otra parte, los mayores incentivos para capacitación tecnológica y mejoras de calidad y productividad en Brasil han ido disminuyendo la brecha en materia de calificación de los recursos humanos, que históricamente favorecía a Argentina. A eso se suma el papel del acceso al crédito, donde las condiciones son mucho más favorables para los exportadores brasileños (Carrera, 2005; Bekerman, Sirlin y Streb, 1995).

En lo que respecta al tipo de comercio que presenta el Mercosur, cabe señalar la consolidación, dentro de los países más grandes, de un intercambio de tipo intraindustrial en ramas como maquinaria, material de transporte e industria química. Esto aparece vinculado, en forma sustancial, a un comercio de tipo intrafirma, administrado o de ambos tipos. Las empresas transnacionales tendieron a especializarse en algunas líneas de productos, complementándose con otras filiales ubicadas principalmente dentro del Mercosur. ${ }^{5}$ Esto está lejos de reflejar la realidad de las pequeñas y medianas empresas (PYME) que solo han accedido marginalmente a las ventajas de pertenecer al bloque, por lo que - hasta ahora- la distribución de beneficios generados por el proceso de integración es claramente desigual según el tamaño de las empresas. ${ }^{6}$

\footnotetext{
${ }^{5}$ Chudnovsky y López (2007) destacan la mayor productividad, los superiores volúmenes de comercio y la mayor capacidad de innovación de las filiales de empresas transnacionales comparadas con las empresas locales.

${ }^{6}$ Este no es un fenómeno que se limite a las exportaciones dentro del Mercosur, sino que refleja una tendencia general. En un estudio de FUNCEX (2005) se observa que, entre 1998 y 2004, el $75 \%$ del crecimiento de las ventas externas brasileñas se debió a grandes empresas que ya estaban participando del comercio exterior.
} 


\section{IV \\ La regionalización de las exportaciones e importaciones entre Argentina y Brasil}

Desde el nacimiento del proceso de integración, Argentina ha presentado un saldo negativo en su comercio de manufacturas industriales con Brasil. Pero durante los últimos 10 años se observa un aumento de ese saldo negativo para la mayor parte de los capítulos industriales de la Nomenclatura Común del Mercosur. Esto puede ofrecer una primera aproximación en cuanto a la consolidación comercial que está mostrando Brasil en el campo de los bienes industriales.

A continuación es interesante observar si estos resultados muestran la misma tendencia al analizarlos mediante los índices de regionalización. Esto permitirá determinar, por una parte, si el incremento del saldo deficitario con Brasil coincide con un crecimiento o una caída en la participación de terceros mercados. Es decir, hasta qué punto está aumentando la importancia de Brasil como proveedor de bienes industriales para Argentina. Por otra parte, puede permitir observar si existen sectores donde Argentina, aun cuando aumentó su déficit comercial con Brasil, logró desarrollar nuevas ventajas comparativas con terceros mercados. En otras palabras, explorar si el Mercosur pudo actuar como plataforma inicial para expandir el comercio o colocar nuevos productos en otros mercados, utilizando para ello el índice de orientación regional. ${ }^{7}$ Esto permite comparar la evolución experimentada por las proporciones exportadas o importadas de Brasil con respecto a las proporciones del resto del mundo. Se consideraron aquellos sectores industriales que mostraron altos niveles de regionalización por parte de las importaciones, de las exportaciones o del comercio intraindustrial durante al menos uno de los dos períodos de análisis: 1997-1998 y $2005-2006 .^{8}$

\footnotetext{
${ }^{7}$ Se trata del mismo índice empleado por Yeats (1997). Véase el Anexo I.

${ }^{8}$ Se seleccionó una muestra que comprende un total de 95 posiciones, 87 a 4 dígitos y 8 a 6 dígitos. La apertura a 6 dígitos se realizó para aquellos ítems que por su importancia merecían realizar una apertura mayor. La intención del trabajo fue mostrar aquellas posiciones relevantes a 4 dígitos e incluir, en los casos en que su relevancia fuese elevada, algunas posiciones a 6 dígitos. El objetivo detrás de esta elección es resaltar que en algunas posiciones a 4 dígitos el peso está
}

\section{Evolución de las importaciones argentinas que muestran alta regionalización}

Se presentan aquí las importaciones que, en el período en estudio, han aumentado ostensiblemente su regionalización con Brasil. Luego, se analizarán aquellas que, a pesar de mantener un alto nivel de regionalización, muestran una disminución en su índice de orientación regional.

\section{a) Aumento de la regionalización}

La gran cantidad de posiciones que presentan un incremento de la regionalización a partir de procesos de desvío y de creación de comercio evidencia hasta qué punto la apertura comercial regional benefició a Brasil (véase el cuadro 1). En efecto, en todas las posiciones de este grupo (con excepción de una) las importaciones argentinas se han acrecentado y en la mayoría de los casos esto coincide con una reducción de aquellas provenientes del resto del mundo. Esto significa que, respecto de estos productos industriales, Brasil no solo logró consolidar sus ventajas comparativas a nivel regional, sino también que el Mercosur contribuyó a que Argentina priorice las compras a ese país, en detrimento de terceros mercados.

Se destacan en este grupo las posiciones correspondientes al capítulo 84, de "calderas, máquinas, aparatos y artefactos mecánicos" y le siguen en importancia los capítulos 72, de "fundición de hierro y acero", y 76, de "aluminio y sus manufacturas".

Dentro del capítulo 84, es notable el desplazamiento de terceros mercados en favor de Brasil de las posiciones correspondientes a refrigeradores, lavadoras, máquinas para cosechar, centrifugadoras, niveladoras y topadoras. Podrían entonces considerarse aquí dos grandes grupos: el de electrodomésticos y el de maquinaria agrícola y para la construcción.

en una o dos posiciones de 6 dígitos y no en todas las posiciones a 6 dígitos que se desprenden de la de 4 . La forma de selección de la muestra puede verse en el Anexo II. 
CUADRO 1

Importaciones argentinas que muestran aumento de la regionalización

(En millones de dólares)

\begin{tabular}{|c|c|c|c|c|c|c|c|c|c|}
\hline \multirow[t]{2}{*}{$\mathrm{NCM}$} & \multirow[t]{2}{*}{ Descripción } & \multicolumn{2}{|c|}{ Desde Brasil(a) } & \multicolumn{2}{|c|}{$\begin{array}{l}\text { Desde el resto } \\
\text { del mundo(b) }\end{array}$} & \multicolumn{2}{|c|}{$\begin{array}{l}\text { Mundo } \\
(\mathrm{c}=\mathrm{a}+\mathrm{b})\end{array}$} & \multicolumn{2}{|c|}{$\begin{array}{c}\text { Proporción M de Brasil } \\
\mathrm{d}=(\mathrm{a} / \mathrm{c}) * 100 \\
(\text { En porcentajes })\end{array}$} \\
\hline & & 1997-1998 & 2005-2006 & 1997-1998 & 2005-2006 & 1997-1998 & 2005-2006 & 1997-1998 & $2005-2006$ \\
\hline 8418 & $\begin{array}{l}\text { Refrigeradores, congeladores y demás } \\
\text { material y máquinas para producción de frío, } \\
\text { excepto aires acondicionados }\end{array}$ & 46,8 & 114,1 & 135 & 54,7 & 181,8 & 168,8 & 25,7 & 67,6 \\
\hline 8421 & $\begin{array}{l}\text { Centrifugadoras, secadoras centrifugas; } \\
\text { aparatos para filtrar o depurar líquidos o gases }\end{array}$ & 18,2 & 29,2 & 141,1 & 101,4 & 159,3 & 130,6 & 11,4 & 22,4 \\
\hline 8433 & $\begin{array}{l}\text { Máquinas, aparatos y artefactos para cosechar } \\
\text { o trillar }\end{array}$ & 56,8 & 115,1 & 100,1 & 67,6 & 156,9 & 182,7 & 36,2 & 63,0 \\
\hline 8450 & Máquinas para lavar ropa, incluso con secado & 17 & 30,5 & 78,5 & 16,4 & 95,5 & 46,9 & 17,8 & 65,0 \\
\hline 842920 & Niveladoras & 16,9 & 30,3 & 19,3 & 11,9 & 36,2 & 42,2 & 46,7 & 71,8 \\
\hline 847149 & $\begin{array}{l}\text { Las demás máquinas automáticas para } \\
\text { tratamiento o procesamiento de datos, } \\
\text { digitales }\end{array}$ & 0 & 16,5 & 36,7 & 9,2 & 36,7 & 25,7 & 0,0 & 64,2 \\
\hline 7201 & $\begin{array}{l}\text { Fundición en bruto y fundición especular, en } \\
\text { formas primarias }\end{array}$ & 0,1 & 16,2 & 0,2 & 1,1 & 0,3 & 17,3 & 33,3 & 93,6 \\
\hline 7207 & $\begin{array}{l}\text { Productos intermedios de hierro o acero sin } \\
\text { alear }\end{array}$ & 80,3 & 96 & 32,1 & 12,1 & 112,4 & 108,1 & 71,4 & 88,8 \\
\hline 7210 & $\begin{array}{l}\text { Productos laminados planos de hierro o acero } \\
\text { sin alear }\end{array}$ & 13,5 & 24,5 & 19,2 & 5 & 32,7 & 29,5 & 41,3 & 83,1 \\
\hline 7214 & $\begin{array}{l}\text { Barras de hierro o acero sin alear, forjadas, } \\
\text { laminadas o extrudidas }\end{array}$ & 12,3 & 9,9 & 9,4 & 2,2 & 21,7 & 12,1 & 56,7 & 81,8 \\
\hline 721934 & $\begin{array}{l}\text { Productos laminados planos de acero } \\
\text { inoxidable }\end{array}$ & 7,4 & 19,7 & 11 & 5,6 & 18,4 & 25,3 & 40,2 & 77,9 \\
\hline 7606 & Chapas y tiras de aluminio & 11,3 & 19,9 & 40,8 & 8 & 52,1 & 27,9 & 21,7 & 71,3 \\
\hline 7616 & Las demás manufacturas de aluminio & 0,8 & 12,6 & 14,7 & 10,7 & 15,5 & 23,3 & 5,2 & 54,1 \\
\hline 4804 & Papel y cartón kraft, sin estucar ni recubrir & 64,1 & 70,3 & 35,4 & 19,5 & 99,5 & 89,8 & 64,4 & 78,3 \\
\hline 2818 & $\begin{array}{l}\text { Corindón artificial; óxido e hidróxido de } \\
\text { aluminio }\end{array}$ & 54,4 & 136,6 & 25,9 & 17,2 & 80,3 & 153,8 & 67,7 & 88,8 \\
\hline 8525 & $\begin{array}{l}\text { Aparatos emisores de radiotelefonía, } \\
\text { radiotelegrafía, radiodifusión o televisión }\end{array}$ & 65,5 & 681 & 620 & 668,2 & 685,5 & 1349,2 & 9,6 & 50,5 \\
\hline 520942 & Tejidos de mezclilla & 28,2 & 36,5 & 4,2 & 0,1 & 32,4 & 36,6 & 87,0 & 99,7 \\
\hline 3305 & Preparaciones capilares & 8 & 42,7 & 13,6 & 9 & 21,6 & 51,7 & 37,0 & 82,6 \\
\hline 5501 & Cables de filamentos sintéticos & 0 & 8,9 & 7,4 & 10,8 & 7,4 & 19,7 & 0,0 & 45,2 \\
\hline 2902 & Hidrocarburos cíclicos & 22,6 & 68,2 & 10,2 & 2,7 & 32,8 & 70,9 & 68,9 & 96,2 \\
\hline 7312 & $\begin{array}{l}\text { Cables, trenzas y similares, de hierro o acero, } \\
\text { sin aislar para electricidad }\end{array}$ & 6,4 & 16 & 9 & 9,3 & 15,4 & 25,3 & 41,6 & 63,2 \\
\hline 7502 & Níquel en bruto & 0,5 & 10,8 & 3,1 & 6,8 & 3,6 & 17,6 & 13,9 & 61,4 \\
\hline 380830 & $\begin{array}{l}\text { Herbicidas, inhibidores de germinación y } \\
\text { reguladores del crecimiento de las plantas }\end{array}$ & 47 & 51,4 & 131,2 & 43,6 & 178,2 & 95 & 26,4 & 54,1 \\
\hline 6402 & $\begin{array}{l}\text { Los demás calzados con suela y parte superior } \\
\text { de caucho o plástico }\end{array}$ & 34,3 & 69,9 & 35,5 & 39,9 & 69,8 & 109,8 & 49,1 & 63,7 \\
\hline 9401 & Asientos y sus partes & 23,8 & 38,7 & 47,1 & 47,6 & 70,9 & 86,3 & 33,6 & 44,8 \\
\hline Total 25 & 5 productos $(a)$ & 636,2 & 1765,5 & 1580,7 & 1180,6 & 2216,9 & 2946,1 & 28,7 & 59,9 \\
\hline Importa & aciones totales MOI (b) & 6212,1 & 9948,8 & 21472,2 & 17894,7 & 27684,2 & 27843,5 & 22,4 & 35,7 \\
\hline Porcenta & taje en el total $(\mathrm{a} / \mathrm{b})$ & $10,2 \%$ & $17,7 \%$ & $7,4 \%$ & $6,6 \%$ & $8,0 \%$ & $10,6 \%$ & & \\
\hline
\end{tabular}

Fuente: elaboración propia sobre la base de datos del Instituto Nacional de Estadística y Censos (INDEC).

NCM: Nomenclatura Común del Mercosur.

MOI: Manufacturas de origen industrial.

(a) Total de productos analizados en el cuadro.

(b) Importaciones/exportaciones totales.

(a/b) Total de productos analizados en el cuadro/importaciones (o exportaciones según el caso) totales. 
Dentro del cuadro 1 se observan también posiciones respecto de las cuales Argentina ha aumentado sus importaciones tanto desde Brasil como del resto del mundo. El caso más notable es la que incluye a los aparatos de telefonía celular (partida 8525, que registra un crecimiento de más del 1.000\% entre 1997-1998 y 2005-2006). En un contexto que podría caracterizarse como de auge de la telefonía celular, se destaca el notable crecimiento de las importaciones provenientes de Brasil comparado con el registrado desde el resto del mundo. Juegan aquí las estrategias de las empresas multinacionales que —ante políticas regulatorias más beneficiosas y diferentes dimensiones del mercado interno- optaron por instalarse en Brasil. Esto fue creando un escenario propicio para la exportación, lo que determinó un considerable desvío de comercio de las importaciones argentinas provenientes de otras zonas (como el sudeste asiático, los Estados Unidos o México) en favor de Brasil. Hacia 2005, el 70\% de los teléfonos celulares importados por Argentina provenían de su principal socio.

Sin embargo, el índice de regionalización correspondiente a las exportaciones de celulares de Brasil a Argentina disminuyó debido al espectacular crecimiento de las exportaciones hacia el resto del mundo. Pero en ese contexto no puede negarse el aporte de la existencia del Mercosur en la adquisición de ventajas comparativas dinámicas en dicho sector. Es que, desde una situación inicial en que sus exportaciones se dirigían casi exclusivamente a Argentina, Brasil llega a consolidarse como exportador competitivo en terceros mercados: sus exportaciones al resto del mundo de esta posición pasan de 54 millones a 2 mil millones de dólares ғОв entre los dos períodos bajo estudio. ${ }^{9}$

\section{b) Disminución de la regionalización}

Las posiciones de la muestra seleccionada que presentan una caída en el índice de orientación regional entre 1997-1998 y 2005-2006 pueden verse en el cuadro 2. La mayor cantidad de casos se explican por una caída en las importaciones desde Brasil, que es proporcionalmente mayor que la que sufren las del resto del mundo. Se trata de posiciones que denotan procesos de sustitución de importaciones por producción nacional e incluyen a sectores como los de ropa de cama, máquinas para lavar vajilla y ciertos tipos de papel.

\footnotetext{
${ }^{9} \mathrm{El}$ comportamiento de las exportaciones brasileñas de estas posiciones hacia el resto del mundo y su índice de regionalización con Argentina pueden verse en el Anexo III.
}

Se presentan, además, aquellas posiciones en donde si bien el índice descendió, tanto las importaciones desde Brasil como las provenientes del resto del mundo aumentaron, pero estas últimas en una proporción mayor.

Dentro de este grupo se destaca el caso de los medicamentos, rubro en el que el grueso de las importaciones del Mercosur provienen del resto del mundo. Se observa aquí como estrategia de las empresas multinacionales, la de no producir en la región los principios activos o las materias primas farmacéuticas en favor de una política de importación negociada a nivel intrafirma (Bekerman y Sirlin, 1999).

\section{Evolución de las exportaciones argentinas que muestran alta regionalización}

Se presentan aquí, en primer lugar, las exportaciones argentinas cuya regionalización con Brasil ha aumentado. En segundo lugar, se analizarán aquellas que, pese a mantener un alto nivel de regionalización, muestran una caída en su índice de orientación regional entre los períodos bajo estudio.

\section{a) Aumento de la regionalización}

En el cuadro 3 se aprecian las posiciones cuyo índice de orientación regional aumentó entre 1997-1998 y 2005-2006, es decir, las posiciones en que se profundizó el proceso de regionalización con Brasil.

En este caso, llama la atención la escasez de posiciones en las que se observa un aumento de la regionalización de exportaciones a Brasil. En todos los casos (a excepción de la posición 8482) las exportaciones totales crecen y, si bien se trata de partidas en las que Brasil sigue siendo el principal destino, se observa que Argentina logró, en algunos casos, acrecentar sus exportaciones al resto del mundo.

Entre estas posiciones se encuentran los "artículos para el transporte o envasado de plásticos", que registran los mayores valores exportados. Sin embargo, el crecimiento más pronunciado lo representan los productos químicos agrupados en la posición "iniciadores y aceleradores de reacción, y preparaciones catalíticas”, que pasan de menos de 1 millón de dólares FOB exportados a Brasil y al resto del mundo a casi 33 millones y 20 millones de dólares FOB, respectivamente.

\section{b) Disminución de la regionalización}

En el cuadro 4 se presentan las posiciones de este grupo de exportaciones cuyo índice de orientación regional cayó entre 1997-1998 y 2005-2006. Nuevamente nos encontramos con una escasa cantidad de posiciones que, 
CUADRO 2

Importaciones argentinas que muestran disminución de su regionalización

(En millones de dólares)

\begin{tabular}{|c|c|c|c|c|c|}
\hline \multirow[t]{2}{*}{ NCM4 } & \multirow[t]{2}{*}{ Descripción } & $\begin{array}{c}\text { Desde } \\
\text { Brasil(a) }\end{array}$ & $\begin{array}{l}\text { Desde el resto } \\
\text { del mundo(b) }\end{array}$ & $\begin{array}{l}\text { Mundo } \\
(\mathrm{c}=\mathrm{a}+\mathrm{b})\end{array}$ & $\begin{array}{c}\text { Proporción M a Brasil } \\
\mathrm{d}=(\mathrm{a} / \mathrm{c}) * 100 \\
(\text { En porcentajes })\end{array}$ \\
\hline & & $1997-1998$ 2005-2006 & $1997-1998 \quad 2005-2006$ & $1997-1998 \quad 2005-2006$ & $1997-19982005-2006$ \\
\hline
\end{tabular}

4818 Papel del tipo de los utilizados para papel higiénico y papeles similares

8422 Máquinas para lavar vajilla; máquinas y aparatos para limpiar o secar botellas o demás recipientes

7209 Productos laminados planos de hierro o acero sin alear

3004 Medicamentos constituidos por productos mezclados o sin mezclar, preparados para usos terapéuticos o profilácticos

2910 Epóxidos, epoxialcoholes, epoxifenoles y epoxieteres

3703 Papel, cartón y textiles, fotográficos, sensibilizados, sin impresionar

6302 Ropa de cama, mesa, tocador o cocina

8212 Navajas y máquinas de afeitar y sus hojas (incluidos los esbozos en fleje)

\begin{tabular}{|c|c|c|c|c|c|c|c|}
\hline 13,2 & 8,3 & 38,2 & 20,7 & 51,4 & 29 & 25,7 & 28,6 \\
\hline 9,8 & 7,2 & 123,4 & 69 & 133,2 & 76,2 & 7,4 & 9,4 \\
\hline 23,9 & 2,1 & 7,8 & 0,8 & 31,7 & 2,9 & 75,4 & 72,4 \\
\hline 59,6 & 62,5 & 290,2 & 353,2 & 349,8 & 415,7 & 17,0 & 15,0 \\
\hline 10,5 & 20,4 & 1,9 & 5,1 & 12,4 & 25,5 & 84,7 & 80,0 \\
\hline 15,7 & 11,6 & 10,8 & 10,4 & 26,5 & 22 & 59,2 & 52,7 \\
\hline 44,4 & 41,7 & 7,2 & 4 & 51,6 & 45,7 & 86,0 & 91,2 \\
\hline 26,9 & 23,6 & 12,9 & 11,1 & 39,8 & 34,7 & 67,6 & 68,0 \\
\hline 204 & 177,4 & 492,4 & 474,3 & 696,4 & 651,7 & 29,3 & 27,2 \\
\hline 6212,1 & 9948,8 & 21472,2 & 17894,7 & 27684,2 & 27843,5 & 22,4 & 35,7 \\
\hline $3,3 \%$ & $1,8 \%$ & $2,3 \%$ & $2,7 \%$ & $2,5 \%$ & $2,3 \%$ & & \\
\hline
\end{tabular}

Total 8 productos (a)

Importaciones totales MOI (a)

Porcentaje en el total $(\mathrm{a} / \mathrm{b})$

$\begin{array}{lrrrrr}3,1 & 9948,8 & 21472,2 & 17894,7 & 27684,2 & 27843,5 \\ 3,3 \% & 1,8 \% & 2,3 \% & 2,7 \% & 2,5 \% & 2,3 \%\end{array}$

Fuente: elaboración propia sobre la base de datos del Instituto Nacional de Estadística y Censos (INDEC).

NCM: Nomenclatura Común del Mercosur.

MOI: Manufacturas de origen industrial.

(a) Total de productos analizados en el cuadro.

(b) Importaciones/exportaciones totales.

(a/b) Total de productos analizados en el cuadro/importaciones (o exportaciones según el caso) totales.

CUADRO 3

Exportaciones argentinas que muestran un aumento de su regionalización (En millones de dólares)

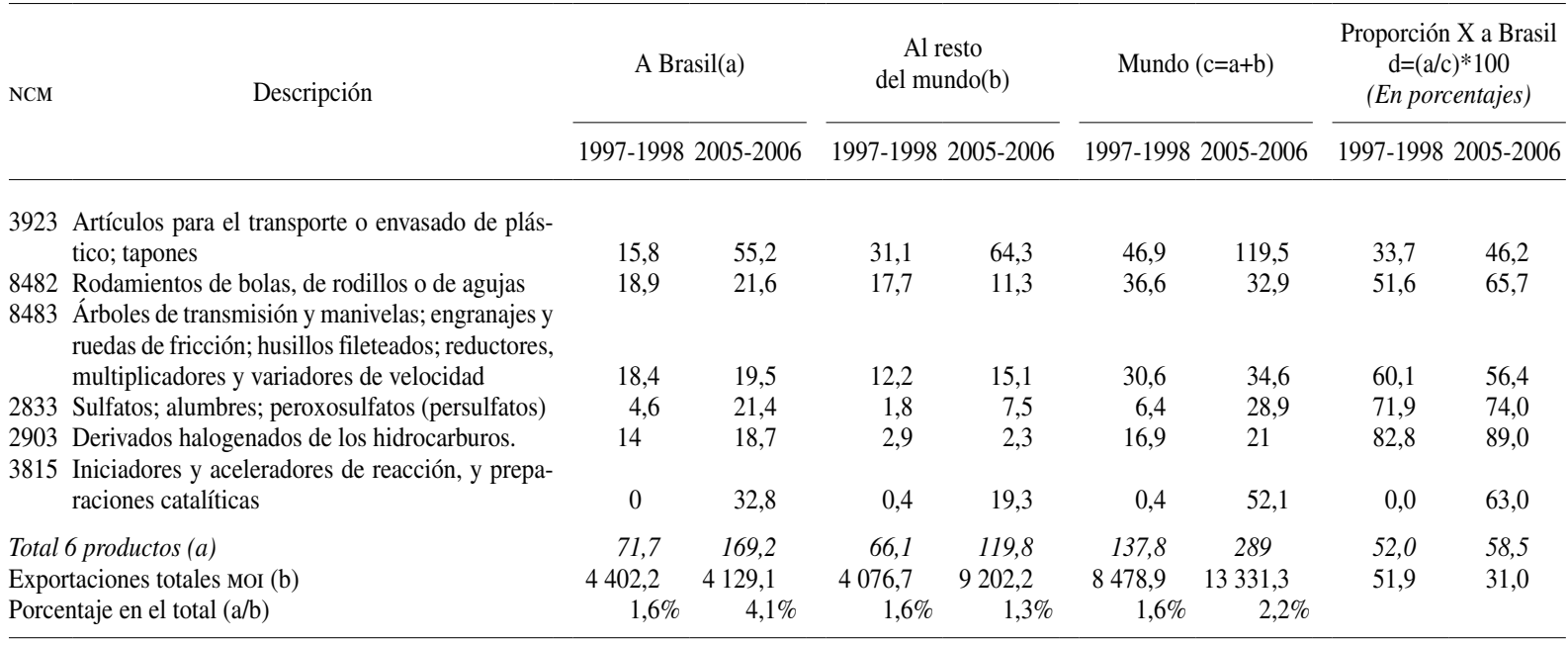

Fuente: elaboración propia sobre la base de datos del Instituto Nacional de Estadística y Censos (INDEC).

NCM: Nomenclatura Común del Mercosur.

MOI: Manufacturas de origen industrial.

(a) Total de productos analizados en el cuadro.

(b) Importaciones/exportaciones totales.

(a/b) Total de productos analizados en el cuadro/importaciones (o exportaciones según el caso) totales. 


\begin{tabular}{|c|c|c|c|c|c|c|c|c|c|}
\hline \multirow[t]{2}{*}{$\mathrm{NCM}$} & \multirow[t]{2}{*}{ Descripción } & \multicolumn{2}{|c|}{ A Brasil $^{\mathrm{a}}$} & \multicolumn{2}{|c|}{$\mathrm{Al}$ resto del mundo ${ }^{\mathrm{b}}$} & \multicolumn{2}{|c|}{ Mundo $o^{c=a+b}$} & \multicolumn{2}{|c|}{$\begin{array}{c}\text { Proporción X a Brasil } \\
\mathrm{d}=(\mathrm{a} / \mathrm{c})^{*} 100 \\
(\text { En porcentajes })\end{array}$} \\
\hline & & 1997-1998 & $2005-2006$ & $1997-1998$ & $2005-2006$ & $1997-1998$ & 2005-2006 & 1997-1998 & $2005-2006$ \\
\hline 3908 & Poliamidas en formas primarias & 64,1 & 70,3 & 0,5 & 23,2 & 64,6 & 93,5 & 99,2 & 75,2 \\
\hline 8419 & $\begin{array}{l}\text { Aparatos y dispositivos para el tratamiento de } \\
\text { materias mediante operaciones que impliquen } \\
\text { un cambio de temperatura }\end{array}$ & 54,4 & 136,6 & 13,6 & 32 & 68 & 168,6 & 80,0 & 81,0 \\
\hline 7612 & $\begin{array}{l}\text { Depósitos, barriles, bidones, cajas y } \\
\text { recipientes similares de aluminio }\end{array}$ & 65,5 & 681 & 1,7 & 9,9 & 67,2 & 690,9 & 97,5 & 98,6 \\
\hline 8536 & $\begin{array}{l}\text { Aparatos para corte, seccionamiento, } \\
\text { protección, derivación, empalme o conexión } \\
\text { de circuitos eléctricos }\end{array}$ & 28,2 & 36,5 & 9,7 & 15,4 & 37,9 & 51,9 & 74,4 & 70,3 \\
\hline 8527 & $\begin{array}{l}\text { Aparatos receptores de radiotelefonía, } \\
\text { radiotelegrafía o radiodifusión }\end{array}$ & 56,8 & 115,1 & 2,4 & 5,6 & 59,2 & 120,7 & 95,9 & 95,4 \\
\hline 3919 & $\begin{array}{l}\text { Placas, láminas, hojas, cintas, autoadhesivas } \\
\text { de plástico. }\end{array}$ & 8 & 42,7 & 6,2 & 28,8 & 14,2 & 71,5 & 56,3 & 59,7 \\
\hline \multicolumn{2}{|c|}{ Total 6 productos $(a)$} & 277 & 1082,2 & 34,1 & 114,9 & 311,1 & 1197,1 & 89,0 & 90,4 \\
\hline \multicolumn{2}{|c|}{ Exportaciones Totales MOI (b) } & 4402,2 & 4129,1 & 4076,7 & 9202,2 & 8478,9 & 13331,3 & 51,9 & 31,0 \\
\hline \multicolumn{2}{|c|}{ Porcentaje en el total $(\mathrm{a} / \mathrm{b})$} & $6,3 \%$ & $26,2 \%$ & $0,8 \%$ & $1,2 \%$ & $3,7 \%$ & $9,0 \%$ & & \\
\hline
\end{tabular}

Fuente: elaboración propia sobre la base de datos del Instituto Nacional de Estadística y Censos (INDEC).

NCM: Nomenclatura Común del Mercosur.

MOI: Manufacturas de origen industrial.

(a) Total de productos analizados en el cuadro.

(b) Importaciones/exportaciones totales.

(a/b) Total de productos analizados en el cuadro/ importaciones (o exportaciones según el caso) totales.

si bien muestran valores exportados pequeños, registran un importante crecimiento en porcentaje.

La caída del índice de orientación regional en todas las posiciones de este grupo se debe principalmente a un aumento en una proporción mayor de las exportaciones argentinas al resto del mundo, ya que ninguna experimentó un descenso en sus exportaciones a Brasil. Se destaca el caso de las poliamidas en formas primarias (una clase de manufactura de plástico) cuyas exportaciones al resto del mundo superaron los 23 millones de dólares FOB en el bienio en 2005-2006. Cabe destacar que en 1997-1998 esas exportaciones eran casi insignificantes.

Esta expansión del comercio al resto del mundo podría evidenciar el desarrollo de procesos de aprendizaje dentro de las exportaciones argentinas.

\section{Evolución comercial de las posiciones con comercio intraindustrial que muestran altos niveles de regionalización}

Se analizarán aquí las posiciones con altos índices de regionalización que evidencian un comercio bilateral de tipo intraindustrial, es decir, aquellas que registran valores significativos tanto para las importaciones argentinas provenientes de Brasil como para las exportaciones dirigidas a dicho país. En el cuadro 5 se intenta resumir, en sus cuatro cuadrantes, las diferentes evoluciones que han tenido los principales productos que componen el comercio intraindustrial entre Argentina y Brasil (los dos cuadrantes superiores muestran un aumento en la regionalización de las importaciones provenientes de Brasil, mientras que los dos cuadrantes inferiores denotan su disminución). A continuación, cada cuadrante será tratado por separado, y con un mayor grado de desagregación, para analizar lo sucedido con las posiciones incluidas en ellos. ${ }^{10}$

a) Cuadrante 1: aumento de los índices de regionalización de importaciones y de exportaciones

En este caso, el incremento de los índices de regionalización obedece a una expansión generalizada del comercio, ya que respecto de Brasil todas las posiciones registran un aumento tanto en las exportaciones como en las importaciones. En el caso de las exportaciones, el aumento de dicho índice se debió a una expansión de las

\footnotetext{
${ }^{10}$ Dado el escaso valor de los montos comercializados en el cuadrante 4 , este no se incluirá en el análisis.
} 
Evolución del índice de orientación regional para partidas que muestran comercio intraindustrial

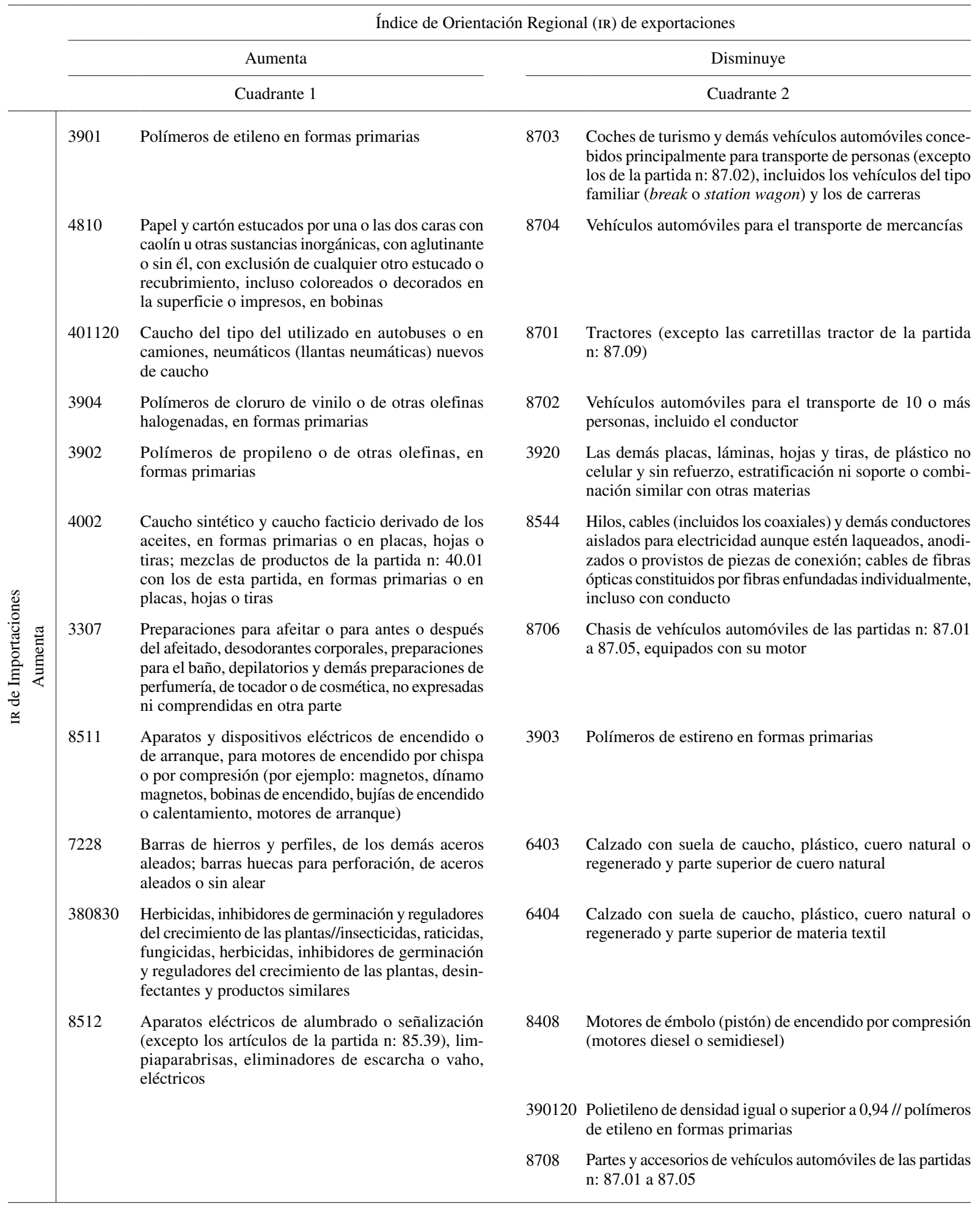


(continuación)

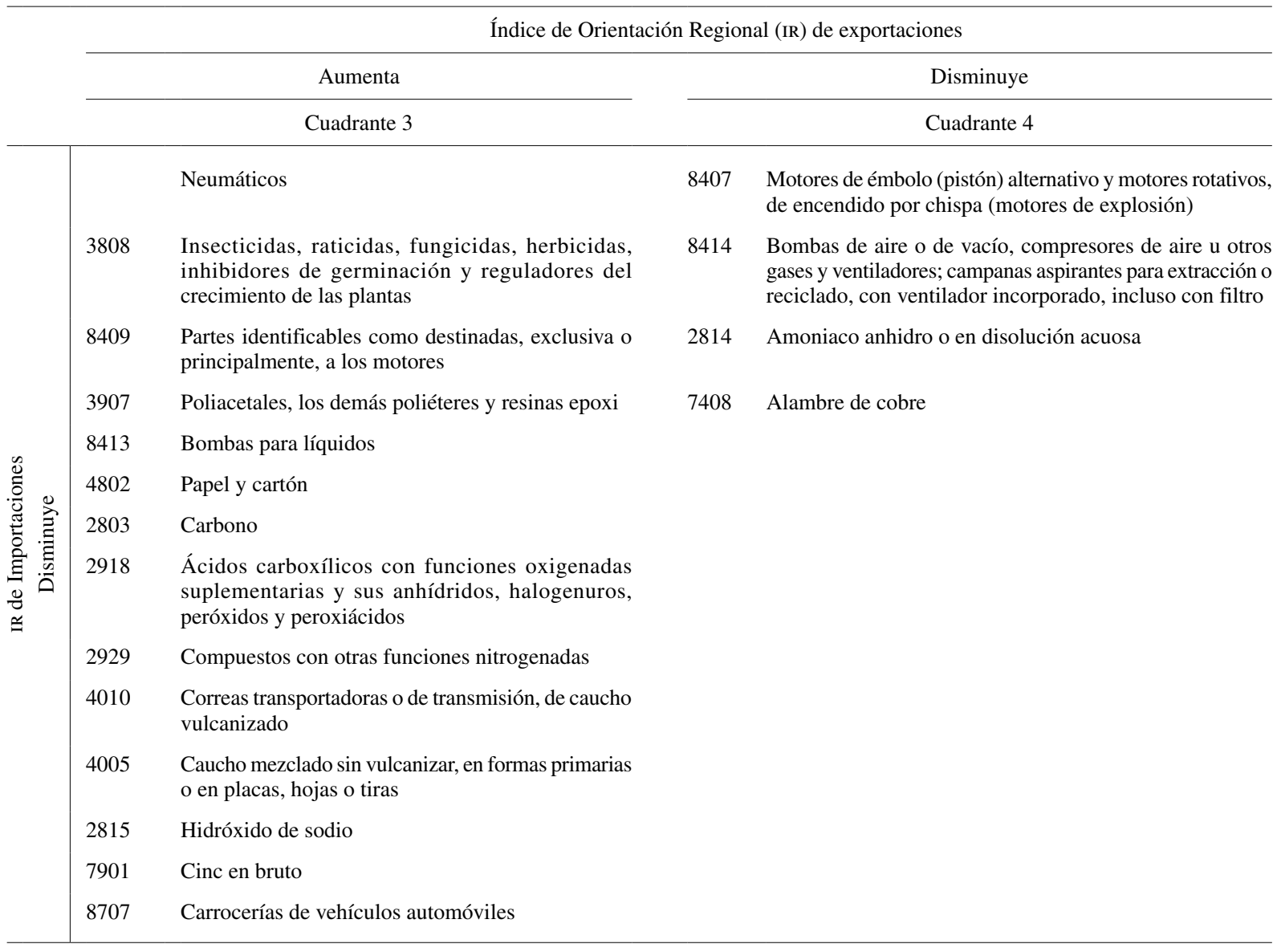

Fuente: elaboración propia sobre la base de datos del Instituto Nacional de Estadística y Censos (INDEC).

ventas argentinas a Brasil en una proporción mayor que la registrada respecto del resto del mundo. En cambio, en el caso de las importaciones, el alza de aquellas provenientes de Brasil coincidió con una reducción de las del resto del mundo.

Dentro de las exportaciones se destaca el crecimiento de los polímeros de etileno en formas primarias (de 15 millones a 270 millones de dólares FOB exportados a Brasil y de 18 millones a 92 millones de dólares FOB en las exportaciones al resto del mundo). Al mismo tiempo, esta posición duplica con creces sus importaciones desde Brasil (de 116 millones a 263 millones de dólares FOB), en tanto que caen las importaciones desde el resto del mundo. El aumento del comercio de este producto básico (commodity) señala un intenso proceso de creación de comercio tanto dentro del Mercosur para Brasil, como dentro y fuera de este bloque para Argentina.

El gran incremento de las exportaciones de polímeros también se extiende a las de cloruro de vinilo y de propilenos. En estas posiciones, si bien se presentan exportaciones menores que las correspondientes a polímeros de etileno - tanto a Brasil como al resto del mundo-, se aprecian crecimientos muy significativos que superan a los que registran las importaciones desde Brasil.

Una posición cuyo crecimiento se centró principalmente en las exportaciones generando casi una primacía para Argentina en este rubro, es la correspondiente a preparaciones para afeitar. Se trata nuevamente de un efecto de las estrategias de las empresas multinacionales que, mediante un proceso de división del trabajo regional, priorizaron a Argentina en la producción de este subsegmento.

Encontramos también aquí posiciones del capítulo "máquinas, aparatos y material eléctrico", que presentan un crecimiento en el comercio con Brasil (tanto exportaciones como importaciones), lo que contrarresta la caída del comercio con el resto del mundo. 


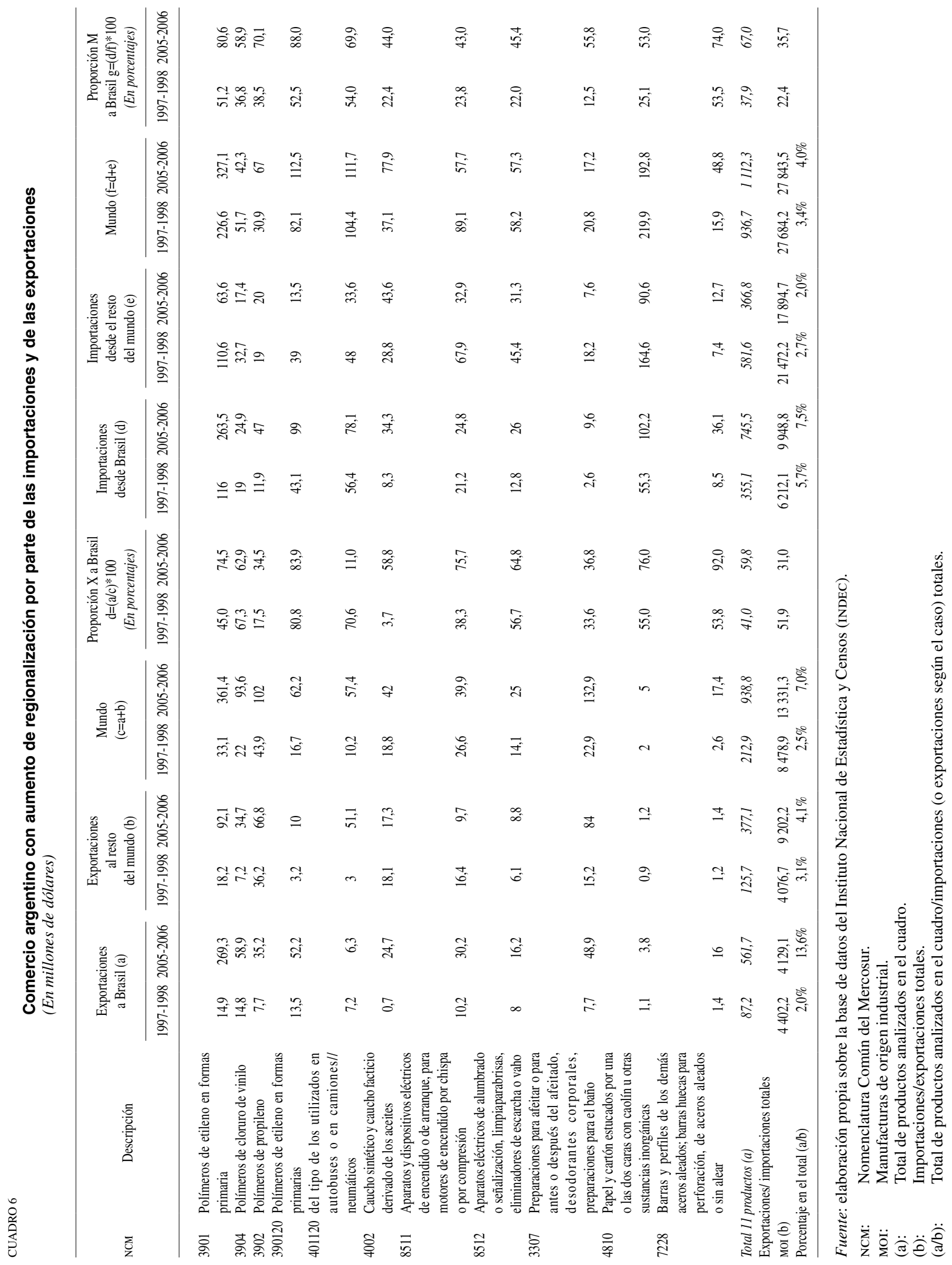


Se puede observar, entonces, un pronunciado incremento de las exportaciones tanto a Brasil como al resto del mundo, lo que revela un proceso de intensa creación de comercio para estas posiciones. En cambio, en cuanto a las importaciones, se observa una tendencia al aumento de las importaciones desde Brasil y a una reducción de las del resto del mundo. Es decir, un proceso de desvío favorable a este socio comercial.

b) Cuadrante 2: aumento del índice regional de importaciones y disminución del de exportaciones

En lo referente a las exportaciones, lo que resalta en este cuadrante es que en la mayoría de las posiciones se advierte una caída de las ventas a Brasil, junto con un marcado aumento de las exportaciones al resto del mundo. Lo inverso sucede con las importaciones, donde crecen todas las posiciones provenientes de Brasil al tiempo que retroceden (salvo una) las importaciones desde el resto del mundo. Este comportamiento revela que mientras Argentina está perdiendo posiciones en Brasil, aunque logra reasignarlas hacia el resto del mundo, su mayor socio comercial se está imponiendo como principal proveedor por sobre terceros mercados. Tal vez en ambos casos se presentan claros ejemplos de expansión comercial, pero con una orientación regional muy diferente, ya que Argentina se provee en forma creciente de bienes provenientes de Brasil, mientras que este socio lo hace a partir de terceros mercados.

Se destacan en este cuadrante distintas posiciones de la industria automotriz ("transporte de pasajeros y de mercancías, tractores y ciertas piezas para vehículos"). Si bien gran parte de la explicación de este fenómeno surge a partir del comportamiento de empresas multinacionales, hay que señalar que en Argentina se observa el desarrollo de estrategias que han permitido aumentar las exportaciones al resto del mundo, estrategias que tal vez no hubieran tenido lugar en ausencia del proceso de integración. Por otra parte, la especialización desarrollada por Brasil en autos familiares y de baja gama favoreció sus ventas a Argentina, ya que constituyen gran parte de las colocaciones dirigidas a ese país.

Dentro de las demás posiciones de este grupo, en los plásticos (polímeros de estireno y placas, láminas, hojas y tiras) y cables conductores de electricidad vuelve a apreciarse un notorio crecimiento de las importaciones desde Brasil, junto con un marcado aumento de las exportaciones argentinas al resto del mundo.

Con respecto a sectores integrados principalmente por pequeñas y medianas empresas, en este cuadro se denotan algunas posiciones del capítulo de calzado donde vuelve a observarse que Brasil logra que sus productores locales saquen mayor provecho de la integración (las importaciones argentinas desde Brasil aumentaron, mientras que se redujeron las provenientes del resto del mundo). Por el contrario, en el caso argentino, las exportaciones cayeron casi al punto de perder por completo los mercados tanto brasileño como del resto del mundo.

c) Cuadrante 3: aumento del índice de regionalización de exportaciones y disminución del de importaciones

En este cuadrante se destaca que casi la totalidad de las posiciones presentan un incremento tanto de las exportaciones a Brasil como de aquellas al resto del mundo.

Esta situación contrasta con el planteamiento de Yeats (1997), ya que el comercio dentro del Mercosur para el que — según este autor-Argentina no contaba con ventajas comparativas estáticas, pudo contribuir a expandir su comercio con terceros mercados. Esto se refleja en el hecho de que el aumento de las exportaciones a Brasil (intrarregional) se ve acompañado de un incremento hacia el resto del mundo (extrarregional).

En este cuadro, respecto de las importaciones no hay una tendencia clara. Existen situaciones de caída $\mathrm{y}$ crecimiento de las importaciones desde Brasil que se combinan con descensos y aumentos de las importaciones desde el resto del mundo.

Al nivel de capítulos, predominan los ya mencionados productos químicos que presentan incrementos en las exportaciones argentinas a todos los destinos, al igual que los plásticos aquí contenidos (poliacetales y polietileno). Por otra parte, el capítulo "caucho y sus manufacturas" registra un importante aumento de las exportaciones, que de ser casi nulas pasan a rondar los 10 millones de dólares FOB a Brasil.

Igual evolución se observa tanto para las exportaciones de piezas para vehículos ( 8707 y 8708) como para las de posiciones del capítulo 84 ("calderas, máquinas, aparatos y artefactos mecánicos”). Además, de los valores importados de estos dos grupos se han reducido, principalmente, las posiciones correspondientes a la industria automotriz, mostrando un proceso de sustitución de importaciones al tiempo que se desarrollaron nuevas ventajas comparativas que permiten ampliar los destinos de las exportaciones. 


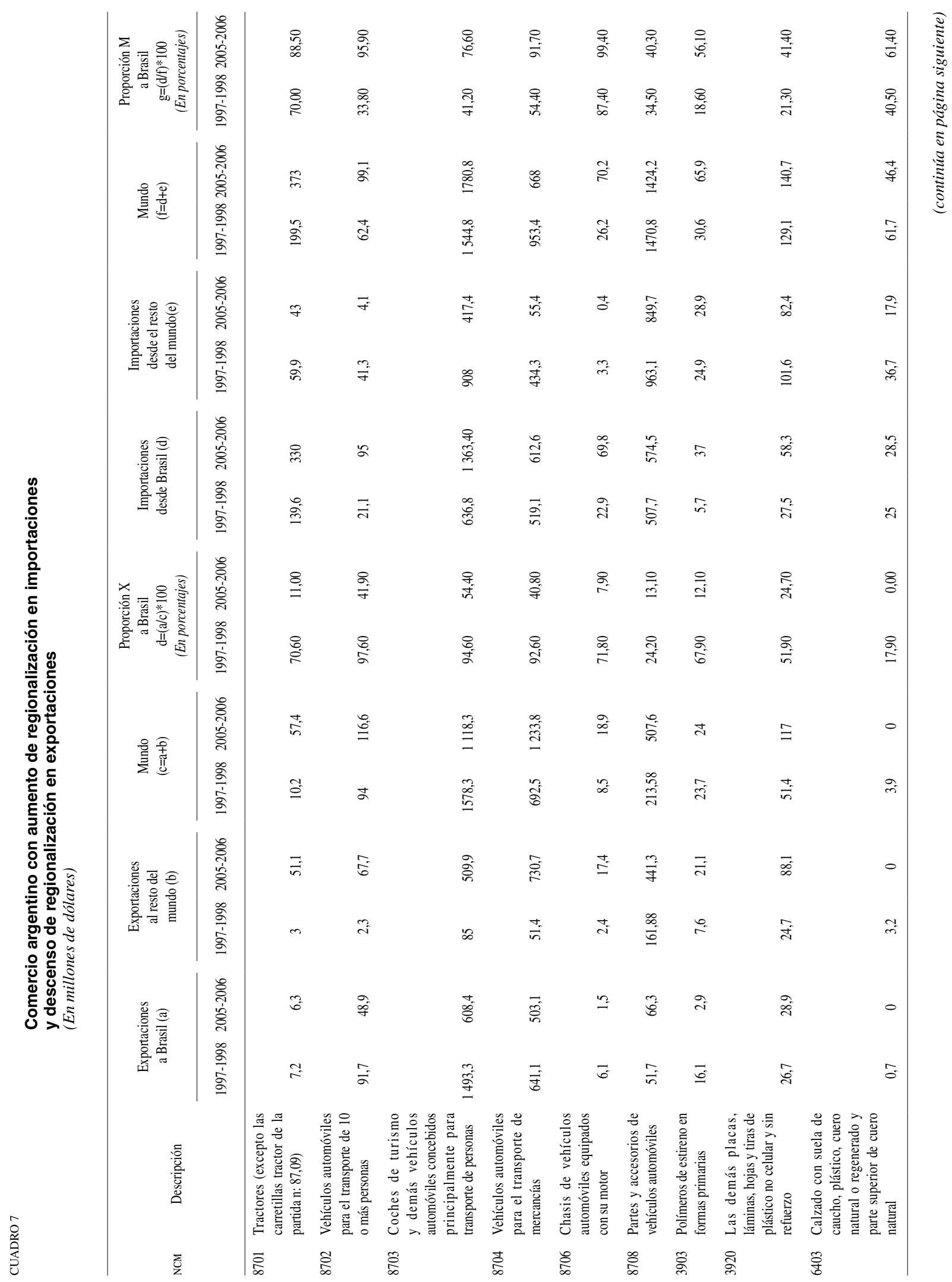




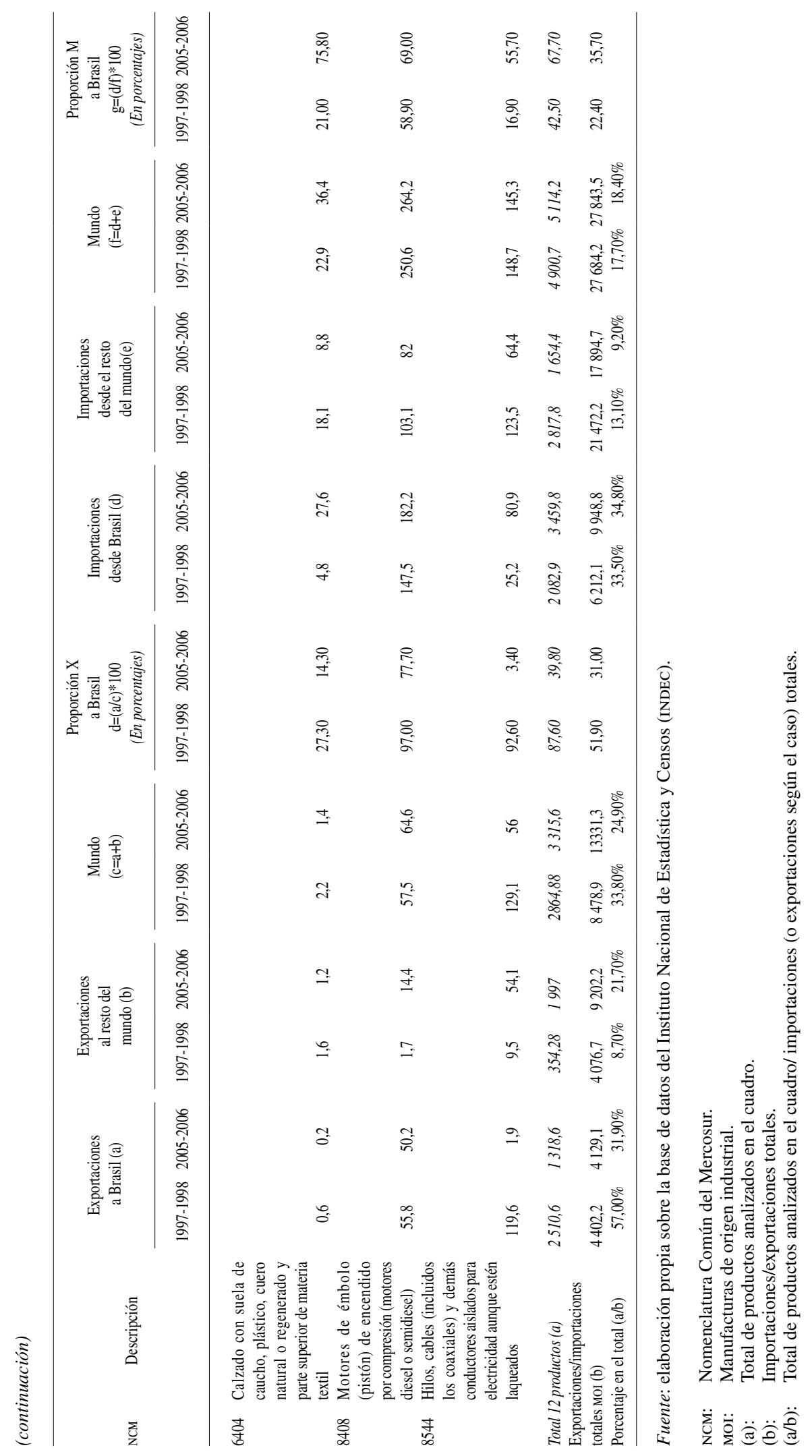




\section{V}

\section{Análisis de la regionalización comercial de Argentina con Uruguay y Paraguay, respectivamente}

El propósito de este apartado es señalar algunas cuestiones relevantes acerca del comercio de Argentina con Uruguay y Paraguay, respectivamente. En primer lugar y a diferencia de Brasil, Argentina presenta un marcado saldo positivo en su balanza comercial con estos socios en el período en estudio. Así, ellos representan para Argentina un mercado al que exporta una interesante variedad de productos, mientras que las importaciones desde estos destinos son poco significativas en monto, especialmente si se las compara con las provenientes de Brasil.

Un dato interesante digno de mencionar respecto del comercio con ambos países, es que dentro de las posiciones a 4 dígitos que respondían a la selección planteada, no hay ninguna posición que haya sido seleccionada como relevante tanto para las importaciones como para las exportaciones argentinas a cada destino.

Se seguirá aquí el mismo esquema de análisis planteado con Brasil. Conviene señalar que el análisis del comercio entre Argentina y Uruguay y Paraguay, respectivamente, no reviste la misma importancia que el realizado con Brasil. Esto se evidencia al observar que no hay suficientes casos significativos como los que se encuentran con el socio mayor del Mercosur.

\section{Evolución de las importaciones argentinas desde Uruguay que muestran alta regionalización}

La relevancia de Uruguay como proveedor argentino es escasa. Las posiciones seleccionadas con aumento de la regionalización son pocas y, al mismo tiempo, registran en conjunto una limitada gravitación dentro del total de las importaciones argentinas de las manufacturas de origen industrial (MOI), dado que se trata de productos que presentan valores muy bajos tanto en su importación desde Uruguay como a nivel global. El incremento de la regionalización proviene principalmente de una disminución de las importaciones argentinas desde el resto del mundo.

En cuanto a las posiciones que registran una caída en la regionalización, en la mayoría de los casos presentan una disminución de las importaciones argentinas desde Uruguay junto con un nivel estable de importaciones desde el resto del mundo. Se trata de posiciones que pierden en gran medida su relevancia en el comercio entre ambos países. En ambos casos, la evolución de la regionalización responde a procesos de sustitución de importaciones con producción local realizados por Argentina.

\section{Evolución de las exportaciones argentinas a Uruguay que muestran alta regionalización}

A diferencia de lo ocurrido con las exportaciones a Brasil, es posible observar aquí, en primer lugar, una gran cantidad de posiciones con aumento de la regionalización. Se trata de productos que, en 2005-2006, presentan un importante incremento de su participación dentro del total de las MOI exportadas por Argentina. A su vez, la variedad de productos indica que, si bien existe una regionalización relevante de las exportaciones de Argentina a Uruguay, estas se encuentran diversificadas entre distintas industrias, muchas de las cuales están representadas principalmente por pequeñas y medianas empresas, como en el caso de los rubros textiles, calzado y botellas.

En segundo lugar, a pesar de que los montos exportados no son mayoritariamente significativos, se trata de productos en los que Argentina no detenta durante el período una fuerte posición exportadora hacia terceros mercados. Esto ayuda a explicar el marcado peso de las exportaciones a Uruguay, pese a tratarse de un mercado pequeño.

Al mismo tiempo, es significativa la variedad de rubros para los que la regionalización de las exportaciones argentinas a Uruguay ha descendido. Por una parte, encontramos productos de industria liviana tales como textiles, pinturas y barnices y otros líquidos y cremas para diferentes usos. Por otra, se hallan pequeñas y medianas máquinas tales como calentadores eléctricos, transformadores eléctricos, adaptadores de televisión, entre otras. 
En ambos casos, las exportaciones al país vecino entre períodos se mantienen relativamente estables o crecen en una baja proporción. Además, la exportación de los mismos productos al resto del mundo presenta un importante aumento que explica el descenso de la regionalización debido al desarrollo del comercio a otros destinos. Es posible que el proceso de aprendizaje permitido por la existencia del Mercosur haya brindado el conocimiento necesario para comenzar a desarrollar ventajas comparativas dinámicas en estos rubros.

\section{Evolución de las importaciones argentinas desde Paraguay que muestran alta regionalización}

$\mathrm{Al}$ igual que en el caso uruguayo, durante el período estudiado se observan pocas posiciones con aumento de su regionalización. Paraguay no es un proveedor prioritario para Argentina y el tipo de productos importados, vinculados sobre todo a la industria textil, parece reflejar que los altos niveles de regionalización responden a la cercanía de ambos mercados. De hecho, el incremento de la regionalización al que se asiste entre los años estudiados se vincula principalmente a la disminución de las importaciones argentinas desde el resto del mundo, que muestra el avance de un proceso de sustitución de importaciones y no a un gran crecimiento en el comercio con su socio.

De la misma manera, se observa una escasa cantidad de posiciones cuya regionalización (antes elevada) cae entre los períodos en estudio. Esto refuerza lo planteado anteriormente en cuanto al papel menor que ocupa Paraguay como proveedor de productos industriales a

\section{VI}

\section{Conclusiones}

La orientación de este trabajo fue analizar, desde la perspectiva de Argentina, hasta qué punto la vigencia de un patrón de especialización comercial —más diversificado en su comercio con Brasil que el que ambos países presentaban frente a los países desarrolladosdio lugar a la generación de ventajas comparativas dinámicas tanto a nivel regional, como en relación con terceros mercados. Para tal efecto se consideró cuál fue la evolución comercial reciente de aquellos bienes industriales que hacia 1998 mostraban altos niveles de regionalización (en importaciones, exportaciones o en
Argentina, pese a ser un socio comercial con aranceles preferenciales.

\section{Evolución de las exportaciones argentinas que muestran alta regionalización con Paraguay}

Al igual que en el caso de las importaciones, las exportaciones argentinas a Paraguay no presentan grados de regionalización significativos, como se refleja en las escasas posiciones con alta regionalización. Sin embargo en algunos casos, como el del calzado, el aumento de la regionalización con Paraguay obedece a una pronunciada caída de las exportaciones argentinas de este producto al resto del mundo (en particular a Brasil, como se evidenció anteriormente). Por último, llama la atención la exportación de celulares (8.525) a Paraguay, que si bien registra valores pequeños, muestra un crecimiento muy importante entre los períodos bajo estudio.

Por otra parte, en concordancia con los resultados anteriores, las posiciones que presentan una pérdida de regionalización se explican, principalmente, por el deterioro de las exportaciones argentinas a Paraguay. Esta caída, que fue acompañada en algunos casos de un aumento de las exportaciones al resto del mundo, resalta que en ciertos casos Paraguay pudo servir de plataforma inicial para generar procesos de aprendizaje en la producción de productos como papel y cartón, cables, máquinas para lavar la ropa y aparatos de mecanoterapia, masajes, entre otros. En este sentido, el comercio con Paraguay, favorecido por la existencia del Mercosur, pudo haber permitido a Argentina acceder a un mercado ampliado y desarrollar ventajas comparativas dinámicas para luego expandir sus exportaciones al exterior del bloque.

ambas) entre dos períodos en estudio: uno previo a las crisis macroeconómicas vividas por ambos países (19971998) y el otro más reciente (2005-2006).

Diez años después de publicado el artículo de Yeats, la experiencia de Brasil (y también, aunque en menor medida, la de Argentina) lejos de confirmar las conclusiones de este autor parece reforzar las ideas de aquellos que consideran que el comercio sur-sur no solo no es perjudicial para el intercambio con terceros países, sino que puede resultar beneficioso para expandirlo y diversificarlo en el mediano y largo plazo. 
Argentina presenta una creciente tendencia a concentrar sus compras de manufacturas industriales en Brasil y a venderlas al resto del mundo. Esto refleja la existencia de un proceso muy asimétrico en cuanto a las tendencias a la regionalización que se aprecian en el comercio bilateral de bienes industriales de los dos principales socios del Mercosur.

Este proceso obedece, en primer lugar, a un aumento en la regionalización de las importaciones industriales argentinas de ciertos rubros, resultado de un incremento en la proporción de importaciones desde Brasil junto con una caída en las originadas en el resto del mundo. En estos rubros Brasil se ha impuesto como principal proveedor. ¿Esto significa, como planteaba Yeats, un desvío ineficiente de comercio proveniente de Brasil o un desarrollo de nuevas ventajas comparativas por parte de este país? Las estadísticas señalan claramente esto último, ya que para los productos industriales señalados Brasil registra también una marcada expansión de sus exportaciones al resto del mundo (con un crecimiento que oscila entre el $80 \%$ y el $300 \%$ ). ${ }^{11}$ Estos datos parecen acercarse más a la perspectiva planteada por Amsden, pues Brasil muestra un marcado desarrollo de procesos de aprendizaje.

El segundo aspecto que cabe destacar en las relaciones comerciales entre Argentina y Brasil es una tendencia a la disminución de la regionalización de diversas exportaciones argentinas. Esto responde, en su mayor parte, a una reducción en las exportaciones a Brasil, pero también a un aumento en las dirigidas al resto del mundo. Por otra parte, puede observarse un incremento en la regionalización de las exportaciones argentinas en ciertos rubros del sector petroquímico, lo que revela la existencia de un proceso muy asimétrico en cuanto a las tendencias a la regionalización en el comercio bilateral de bienes industriales de los dos principales socios del Mercosur.

¿Qué implicancias tendría esta asimetría en una perspectiva de evaluación de impacto del proceso de integración regional? Para Argentina podría significar que, en algunos casos como el de la industria automotriz y de ciertos productos básicos, petroquímicos y plásticos, el Mercosur pudo actuar como plataforma inicial de exportaciones para luego permitir su expansión al resto del mundo. Aquí se pudieron desarrollar procesos de aprendizaje, de mejoramiento en la organización de la producción o de ambos. Desde la perspectiva de Brasil, en un contexto de políticas productivas internas

\footnotetext{
${ }^{11}$ Para mayor detalle véase el Anexo III.
}

que favorecen la competitividad, el Mercosur le brindó claras oportunidades de fortalecer ciertos sectores industriales a partir del desarrollo de economías de escala y aprendizaje. No se puede dejar de tener en cuenta que estas tendencias reflejan las estrategias globalizadoras de las empresas multinacionales, las que mejor han usufructuado hasta ahora de los beneficios del proceso de integración.

Si se realiza un análisis pormenorizado de los resultados obtenidos, en primer lugar, y de acuerdo con los planteamientos que estiman beneficioso el comercio sur-sur de bienes industriales, se destacan las exportaciones de vehículos automotores, sus partes y piezas. La evolución comercial de este tipo de bienes ha sido variada. Lo que en un primer momento ayudó a sostener el superávit comercial bilateral argentino por medio de las crecientes exportaciones a Brasil, hoy muestra una faceta diferente. Mientras las importaciones de autos y piezas (capítulo 87) desde Brasil han crecido considerablemente en los últimos años, las exportaciones argentinas han descendido levemente. Sin embargo, lo que interesa aquí es el importante grado de diversificación logrado por este tipo de exportaciones argentinas al resto del mundo. Aunque Brasil sigue siendo el principal destino de las ventas argentinas de autos y partes, existen otros destinos cuya importancia viene en aumento. En cuanto Brasil comenzó a disminuir las compras de autos y piezas, Argentina pudo desviar y expandir este tipo de exportaciones hacia otros países.

En esta misma línea, los plásticos son otro rubro de importancia particularmente para Argentina. Lo interesante de este grupo de productos es que su producción se encuentra atomizada entre casi 1.700 empresas dentro de las que se destacan las de tamaño pequeño y mediano (Briner, Bustos y Sacroisky, 2007).

A pesar del pronunciado aumento de las importaciones argentinas de bienes industriales desde Brasil, este país presenta un proceso de desregionalización de sus exportaciones a Argentina empujado por el ostensible crecimiento de estas hacia terceros mercados. Mientras que en el período 1997-1998, el 21\% de sus exportaciones de MOI se dirigían a Argentina, este porcentaje se redujo al $15 \%$ en 2005-2006. No puede negarse que, en el caso de ciertos bienes industriales, el comercio con Argentina le dio a Brasil un impulso muy importante para lograr un desarrollo de ventajas comparativas dinámicas y una expansión posterior hacia el resto del mundo.

Por otra parte, desde la perspectiva de Argentina podría señalarse que el seguimiento de las propuestas de exportar en función de las ventajas comparativas 
estáticas (productos primarios y algunas manufacturas de origen agropecuario) le dio pobres resultados en su comercio con Brasil en el mediano plazo. Es más, ese resultado podría haber empeorado de continuar esa estrategia, dado que Brasil se está convirtiendo o bien en autosuficiente, o bien en un fuerte exportador de esos productos. Es así como el importante superávit comercial que mantuvo Argentina durante la década de 1990 fue disminuyendo hasta transformarse, a partir del año 2002, en un déficit conducido por el intercambio de bienes industriales.

En lo que respecta al comercio argentino con Uruguay y Paraguay, se observa que el principal beneficiado ha sido Argentina, porque tanto la cercanía geográfica como la existencia del Mercosur hicieron posible que exportara ciertos productos a sus socios, desarrollando un proceso de aprendizaje mediante las exportaciones (learning by exporting) que luego le permitió expandirlas al resto del mundo. Esto evidencia que para ciertos productos Argentina efectivamente pudo desarrollar ventajas comparativas dinámicas, lo que se ve reforzado por el hecho de que en la actualidad no se encuentran niveles de regionalización significativos entre Argentina y Paraguay y Argentina y Uruguay, respectivamente. Cabe señalar, sin embargo, que Paraguay y Uruguay han quedado en cierta medida relegados en el proceso de desarrollo de ventajas comparativas dinámicas como producto del comercio dentro del bloque.

En definitiva, en este trabajo se hace manifiesto que, para el caso de los socios más grandes, el Mercosur pudo funcionar como instrumento de desarrollo de ventajas comparativas dinámicas. La pregunta, dada la realidad presente, es hasta qué punto el proceso de integración puede continuar cumpliendo ese papel. A su vez, este interrogante se amplía al analizar si dicha integración podría realizarse más equitativamente para el conjunto de los países que integran el bloque, lo que significa reducir las asimetrías de política económica y extender sus beneficios a los socios más pequeños. Estos son los grandes desafíos que plantea hacia adelante el proceso de integración.

ANEXOS

ANEXO I

\section{Índice de orientación regional del comercio}

Para el caso de las exportaciones, el índice es el siguiente:

$I R X_{t}=\frac{X_{i, B R A ; t} / X_{M O I, B R A ; t}}{X_{i, R O W: t} / X_{M O I, R O W ; t}}$

en donde:

IRX $X_{t}$ : Índice de orientación regional en el año $t$

$X_{i, B R A ; t}$ : Exportaciones de producto/partida $i$ a Brasil en el año $t$

$X_{M O I, B R A ;}:$ Exportaciones totales de MOI a Brasil en el año $t$

$X_{i, R O W ; t}:$ Exportaciones de producto/partida $i$ al resto del mundo en el año $t$

$X_{M O I, R O W ; t}:$ Exportaciones totales de MOI al resto del mundo en el año $t$

$Y \sum_{l}^{n} X_{M O I}$, es decir, la suma de todas las partidas $i$ es igual al total de exportaciones de MOI

Para el caso de las importaciones, el procedimiento es análogo.

$\operatorname{IRM}{ }_{t} \frac{M_{i, B R A ; t} / M_{M O I, B R A ; t}}{M_{i, R O W ; t} / M_{M O I, R O W ; t}}$

donde:

$I R M_{t}$ : Índice de orientación regional en el año $t$

$M_{i, B R A ; t}$ : Exportaciones de producto/partida $i$ a Brasil en el año $t$

$M_{M O I, B R A ; t}:$ Exportaciones totales de MOI a Brasil en el año $t$

$M_{i, R O W ; t}:$ Exportaciones de producto/partida $i$ al resto del mundo en el año $t$

$M_{M O I, R O W ; t}:$ Exportaciones totales de MOI al resto del mundo en el año $t$

$Y \sum_{l}^{m} M_{i}=M_{M O I}$, es decir, la suma de todas las partidas $i$ es igual al total de importaciones de MOI

мOI: Manufacturas de origen industrial. 
ANEXO II

\section{Selección de la muestra}

Para realizar este trabajo se utilizó todo el universo de las exportaciones e importaciones argentinas divididas entre las que se comercian con Brasil y aquellas con el resto del mundo. ${ }^{12}$ Dentro de este universo se seleccionó una muestra de exportaciones e importaciones que incluye a aquellas partidas que en algún año —entre el rango de tiempo analizado — hayan superado los 10 millones de dólares. Esto redujo la muestra de exportaciones a 61 posiciones arancelarias que representan en promedio el $85 \%$ de las ventas a Brasil y el $73 \%$ de las ventas al resto del mundo. Por su parte, la muestra de importaciones

${ }^{12}$ De esta manera se conformaron dos grandes grupos, el de exportaciones, compuesto por 919 posiciones arancelarias a cuatro dígitos de acuerdo con la Nomenclatura Común del Mercosur (NCM4), y el de importaciones, que agrupa a 928 posiciones arancelarias de acuerdo con dicha clasificación. quedó reducida a 184 posiciones, que representan en promedio el $90 \%$ de las importaciones provenientes de Brasil, por una parte, y un $65 \%$ de las importaciones provenientes del resto del mundo, por otra.

A su vez, de esa primera selección se utilizaron para el análisis aquellas partidas que registraran un índice de regionalización (ya sea para exportaciones o importaciones) superior a $1{ }^{13} \mathrm{El}$ último criterio de selección consistió en elegir aquellas partidas cuya proporción de importaciones (exportaciones) dentro del bloque con respecto a las importaciones (exportaciones) totales sobrepasara el $30 \%$.

${ }^{13}$ Un índice de regionalización mayor que 1 significa que para esa posición el comercio (exportación o importación, según el caso) se encuentra regionalizado entre Argentina y Brasil.

ANEXO III

Exportaciones brasileñas al resto del mundo de principales capítulos y posiciones industriales exportados a Argentina

\begin{tabular}{|c|c|c|c|c|}
\hline \multicolumn{5}{|c|}{$\begin{array}{l}\text { Exportaciones brasileñas al resto del mundo } \\
\quad(\text { En millones de dólares fob) }\end{array}$} \\
\hline & Capítulo & 1997-1998 & $2005-2006$ & $\begin{array}{l}\text { Variación } \\
\text { entre períodos }\end{array}$ \\
\hline 28 & $\begin{array}{l}\text { Productos químicos inorgánicos; compuestos inorgánicos u orgánicos de los } \\
\text { metales preciosos, de los elementos radiactivos, de metales de las tierras raras o de }\end{array}$ & 3607 & 1 & 23010 \\
\hline 29 & Productos químicos orgánicos & 892,5 & $\begin{array}{l}1620,1 \\
1630,7\end{array}$ & $82.7 \%$ \\
\hline 30 & Productos farmacéuticos & 118,2 & 470,8 & $298,2 \%$ \\
\hline 84 & $\begin{array}{l}\text { Reactores nucleares, calderas, máquinas, aparatos y artefactos mecánicos; partes } \\
\text { de estas máquinas o aparatos }\end{array}$ & 3593,8 & 9068,7 & $152,4 \%$ \\
\hline 85 & $\begin{array}{l}\text { Máquinas, aparatos y material eléctrico y sus partes; aparatos de grabación o de } \\
\text { reproducción de sonido, aparatos de grabación o de reproducción de imágenes y }\end{array}$ & & & \\
\hline & sonido en televisión, y las partes y accesorios & 1426,3 & 4722,4 & $231,1 \%$ \\
\hline 87 & $\begin{array}{l}\text { Vehículos automóviles, tractores, ciclos y demás vehículos terrestres, sus partes y } \\
\text { accesorios }\end{array}$ & 3326,6 & 8828,5 & $165,4 \%$ \\
\hline
\end{tabular}




\section{Exportaciones}

(En millones de dólares $\mathrm{FOB}$ )

\begin{tabular}{|c|c|c|c|c|c|}
\hline & \multirow[t]{2}{*}{ Posición } & \multicolumn{2}{|c|}{$\begin{array}{l}\text { Promedio de } \\
\text { exportaciones brasileñas } \\
\text { a Argentina }\end{array}$} & \multicolumn{2}{|c|}{$\begin{array}{l}\text { Promedio de } \\
\text { exportaciones brasileñas } \\
\text { al resto del mundo }\end{array}$} \\
\hline & & $1997-1998$ & 2005-2006 & 1997-1998 & $2005-2006$ \\
\hline 8418 & $\begin{array}{l}\text { Refrigeradores, congeladores y demás material, máquinas y aparatos para } \\
\text { producción de frío, aunque no sean eléctricos; bombas de calor, excepto } \\
\text { las máquinas y aparatos para acondicionamiento de aire de la partida } \\
\text { n: } 84.15 \text {. }\end{array}$ & 51 & 120 & 63 & 308 \\
\hline 8525 & $\begin{array}{l}\text { Aparatos emisores de radiotelefonía, radiotelegrafía, radiodifusión o } \\
\text { televisión, incluso con aparato receptor o de grabación o reproducción de } \\
\text { sonido incorporados; cámaras de televisión; videocámaras, incluidas las } \\
\text { de imagen fija. }\end{array}$ & 66 & 685 & 54 & 2000 \\
\hline 8701 & Tractores (excepto las carretillas tractor de la partida n: 87.09) & 143 & 338 & 113 & 901 \\
\hline 8702 & $\begin{array}{l}\text { Vehículos automóviles para el transporte de } 10 \text { o más personas, incluido } \\
\text { el conductor. }\end{array}$ & 21 & 96 & 141 & 223 \\
\hline 8703 & $\begin{array}{l}\text { Coches de turismo y demás vehículos automóviles concebidos principalmente } \\
\text { para transporte de personas (excepto los de la partida n: } 87.02 \text { ), incluidos } \\
\text { los vehículos del tipo familiar (break o station wagon) y los de carreras. }\end{array}$ & 649 & 1390 & 892 & 3106 \\
\hline
\end{tabular}

Fuente: elaboración propia sobre la base de datos del Instituto Nacional de Estadística y Censos (INDEC).

\begin{tabular}{lrr}
\hline Posición & \multicolumn{2}{c}{$\begin{array}{c}\text { Índice regional de exportaciones } \\
\text { de Brasil a Argentina }\end{array}$} \\
\hline & $1997-1998$ & $2005-2006$ \\
\hline
\end{tabular}

8418 Refrigeradores, congeladores y demás material, máquinas y aparatos para producción de frío, aunque no sean eléctricos; bombas de calor, excepto las máquinas y aparatos para acondicionamiento de aire de la partida $\mathrm{n}$ : 84.15.

8525 Aparatos emisores de radiotelefonía, radiotelegraía, radiodifusión o televisión, incluso con aparato receptor o de grabación o reproducción de sonido incorporados; cámaras de televisión; videocámaras, incluidas las de imagen fija.

\begin{tabular}{lll}
7,8 & 2,0 \\
& 4,9 & 2,2 \\
& 0,6 & 4,1 \\
& & \\
$\operatorname{los}$ & 2,8 & 2,6 \\
\hline
\end{tabular}

8701 Tractores (excepto las carretillas tractor de la partida n: 87.09)

8702 Vehículos automóviles para el transporte de 10 o más personas, incluido el conductor.

8703 Coches de turismo y demás vehículos automóviles concebidos principalmente para transporte de personas (excepto los de la partida n: 87.02), incluidos los vehículos del tipo familiar (break o station wagon) y los de carreras.

Fuente: elaboración propia sobre la base de datos del Instituto Nacional de Estadística y Censos (INDEC). 
Bibliografía

Amsden, Alice H. (1997), "Bringing production back in understanding government's economic role in late industrialization", World Development, vol. 25, $\mathrm{N}^{\circ} 4$, Amsterdam, Elsevier.

(1976), "Trade in manufactures between developing countries", The Economic Journal, vol. 86, № 344, diciembre, Oxford, Blackwell Publishing.

Bekerman, M. y D. Cerdeiro (2006), "Integración, crisis y patrón de especialización de la economía argentina", Documento de trabajo, $\mathrm{N}^{\circ} 16$, Buenos Aires, Centro de Estudios de la Estructura Económica (CENES), Facultad de Ciencias Económicas, Universidad de Buenos Aires.

Bekerman, M. y H. Montagu (2007), “¿Por qué Argentina pierde terreno en el comercio con Brasil?", Realidad económica, $\mathrm{N}^{\circ}$ 232, Buenos Aires, Instituto Argentino para el Desarrollo Económico (IADE), noviembre-diciembre.

Bekerman, M. y P. Sirlin (1999), "Impactos sectoriales del proceso de integración del Mercosur: los casos del sector calzado y del sector farmacéutico", Documento de trabajo, № 9 , Buenos Aires, Centro de Estudios de la Estructura Económica (CENES), Facultad de Ciencias Económicas, Universidad de Buenos Aires.

Bekerman, M., P. Sirlin y M.L. Streb (1995), "Las nuevas orientaciones de política industrial y de promoción de exportaciones en Argentina y Brasil. Asimetrías y posibilidades de coordinación", Documento de trabajo, $\mathrm{N}^{\circ}$ 1, Buenos Aires, Centro de Estudios de la Estructura Económica (CENES), Facultad de Ciencias Económicas, Universidad de Buenos Aires.

Briner, María Agustina, Magdalena Bustos Zavala y Ariana Sacroisky (2007), "Desafíos de la reconfiguración productiva en Argentina", Documento de trabajo, N ${ }^{\circ} 16$, Buenos Aires, Centro de Economía y Finanzas para el Desarrollo de Argentina (CEFID-AR), julio.

Carrera, Jorge (2005), "Inserción y especialización del sistema productivo argentino en la economía internacional. Modelos productivos", Escenarios de salida de crisis y estrategias alternativas de desarrollo para Argentina, Julio César Neffa y Héctor Cardono, Buenos Aires, Centro de Estudios e Investigaciones Laborales, Programa de Tecnología, Investigaciones Económicas sobre Trabajo y Empleo (CEIL-PIETTE), septiembre.

Castagnino, Tomás (2005), "El comercio exterior de las manufacturas industriales. Estática comparada: 1998-2005”, Revista del CEI, $\mathrm{N}^{\circ} 4$, Buenos Aires, Centro de Economía Internacional, noviembre.

Chudnovsky, Daniel y Andrés López (2007), "Inversión extranjera directa y desarrollo: la experiencia del Mercosur", Revista de la CEPAL, No 92 (LC/G.2339-P), Santiago de Chile, agosto.
Corden, Max (1972), "Economies of scale and customs union theory", The Journal of Political Economy, vol. 80, No 3, Chicago, University of Chicago Press.

Ffrench-Davis, Ricardo (2001), "El comercio intralatinoamericano y su base analítica para el nuevo decenio", Santiago de Chile, borrador.

FUNCEX (Fundación Centro de Estudios de Comercio Exterior) (2005), Boletim de comércio exterior, Río de Janeiro.

Krugman, Paul y Maurice Obstfeld (2001), "Las bases para el comercio: la dotación factorial y el modelo de Heckscher-Ohlin”, Economía internacional, Madrid, Addison Wesley.

Laird, S. (1998), "Mercosur: objectives and achievements", Economics Notes, Washington, D.C., Banco Mundial.

López, Andrés, Gustavo Lugones y Fernando Porta (1993), "Factores macroeconómicos, políticas públicas y estrategias privadas", Comercio y competitividad en el Mercosur, Buenos Aires, Centro de Investigaciones para la Transformación (CENIT), julio.

Nagarajan, Nigel (1998), "La evidencia sobre el desvío de comercio en el Mercosur", Integración y comercio, $\mathrm{N}^{\circ} 6$, Buenos Aires, Instituto para la Integración de América Latina y el Caribe (INTAL), diciembre.

Porta, Fernando (2004), "Una nueva racionalidad: la importancia de la coordinación microeconómica”, Evaluación del desempeño y aportes para un rediseño del Mercosur. Una perspectiva desde los sectores productivos argentinos (LC/BUE/R.258), Bernardo Kosacoff (coord.), Buenos Aires, Oficina de la CEPAL en Buenos Aires.

Ríos, Sandra Polónia (2003), Mercosur: en busca de una nueva agenda. Mercosur: Dilemas y alternativas de la agenda comercial, Buenos Aires, Instituto para la Integración de América Latina y el Caribe ( INTAL), diciembre.

Ríos, Sandra Polónia y Roberto Iglesias (2005), “Anatomia do boom exportador e implicações para a agenda de negociações comerciais do Brasil", Revista brasileira de comércio exterior, Río de Janeiro, Fundación Centro de Estudios de Comercio Exterior (FUNCEX), octubre-diciembre.

Rodrik, Dani (1995), "Las reformas a la política comercial e industrial en los países en desarrollo: una revisión de las teorías y datos recientes", Desarrollo económico, vol. 35, № 138, Buenos Aires, Instituto de Desarrollo Económico y Social (IDES), septiembre-noviembre.

Yeats, Alexander (1997), "Does Mercosur's trade performance raise concerns about the effects of regional trade arrangements?", Policy Research Working Paper, № 1729, Washington, D.C., Banco Mundial, febrero. 